\title{
Caracterização de juntas de compósitos Polieterimida/fibra de carbono submetidos a condicionamentos ambientais
}

\section{Caracterization of composite joints of polyetherimide/carbon fiber subjected to environmental conditioning tests}

Isabela Luiza Rodrigues Cintra ${ }^{1,2 *}$, Ana Beatriz Ramos Moreira Abrahãoํ․ Flávio Felicio da Silva ${ }^{1}$, Marcos Paulo Souza Ribeiro², Luis Felipe Barbosa Marques², Edson Cocchieri Botelho²

\section{RESUMO}

Materiais compósitos possuem boas propriedades como baixo peso e elevada resistência mecânica, o que faz com que sejam cada vez mais estudados para utilização em peças da indústria aeronáutica. Entretanto, devido às condições em que as aeronaves são expostas quando em voo, uma avaliação sistemática de propriedades desses materiais é necessária para tal utilização. Uma das formas de avaliação é submeter os materiais a ensaios de condicionamento ambiental para analisar sua resistência quando expostos a intempéries. Uma das limitações na utilização industrial de compósitos é o uso de processos adequados de união, sendo os mais comuns: união adesiva, fusão e rebitagem. Por possuir vantagens como melhor qualidade da junta e menor custo, o processo de união por fusão se destaca dos demais. Nesse sentido, o presente trabalho visa avaliar a resistência mecânica de juntas do compósito de polieterimida (PEI)/fibra de carbono soldadas por oxiacetileno quando submetidos a ensaios de condicionamentos ambientais, higrotérmico e por radiação ultravioleta.

Palavras-chave:Compósitos Poliméricos, Condicionamento Ambiental, Soldagem.

\begin{abstract}
Composite materials present good properties such as low weight and high strength, which makes them increasingly studied for use in parts of the aeronautical industry. However, due to the conditions under which aircraft are exposed when in flight, an assessment of material properties is required for such use. One of the ways for this assessment is to subject the materials to environmental conditioning tests in order to analyze their mechanical resistance when exposed to weathering. One of the limitations in using composites industrially is the use of suitable bonding processes, the most common being adhesive bonding, melting and riveting. Because it has advantages such as better joint quality and lower cost, the melting joining process stands out from the others. In this sense, this work aims to evaluate the mechanical resistance for polyetherimide (PEI)/carbon fiber composite material welded by oxyacetylene when submitted to hygrothermal and ultraviolet radiation environmental conditioning tests.
\end{abstract}

Keywords: Polymer composites, Environmental conditioning, Welding.

1.Faculdade de Tecnologia de Pindamonhangaba - Laboratório de Eletroquímica e corrosão - Pindamonhangaba (SP), Brasil.

2.Universidade Estadual Paulista "Júlio de Mesquita Filho" - Faculdade de Engenharia de Guaratinguetá - Departamento de Materiais e Tecnologia Guaratinguetá (SP), Brasil.

*Autora correspondente: isabelacintra26@gmail.com

Recebido: 19 Mar 2020 Aceito: 14 Abr 2020 


\section{INTRODUÇÃO}

Por operarem em grandes altitudes, as aeronaves acabam sendo expostas às mais variadas condições atmosféricas, como incidência de raios ultravioleta (UV), baixas temperaturas, variações de umidade e exposição a ambientes ácidos, o que pode resultar na perda das propriedades originais dos materiais utilizados em sua fabricação. As condições ambientais às quais os materiais compósitos são submetidos durante o uso acabam dificultando a análise de suas propriedades mecânicas. Para que os resultados provenientes dos ensaios mecânicos obtidos em laboratório sejam coerentes com os resultados apresentados em serviço, torna-se necessário que as amostram sejam submetidas a diversos condicionamentos ambientais que simulem as condições de trabalho durante o voo ${ }^{1}$.

A umidade do ambiente associada a variações de temperatura consiste em uma das situações mais atuantes em compósitos estruturais, uma vez que pode causar degradação hidrolítica das cadeias poliméricas, formação de ligações cruzadas e plasticização da matriz, sendo a matriz polimérica o componente mais afetado, pois sua estrutura absorve as moléculas de água. A água penetra na matriz polimérica por meio do processo de difusão, sendo a absorção interrompida quando a concentração de equilíbrio entre o material e o meio ambiente é atingida. A movimentação das moléculas no interior da matriz polimérica é o fator responsável pela difusão de umidade de uma região de maior concentração para uma de menor concentração. Como consequência da difusão, as resistências à tração e ao cisalhamento, assim como a rigidez, têm seus valores reduzidos ${ }^{1-4}$.

A ação dos raios UV em compósitos poliméricos pode causar falhas prematuras quando esses materiais são expostos a esse meio, uma vez que ocorrem reações oxidativas que resultam na degradação do material, causando alterações em suas características físicas (fragilização mecânica e formação de fissuras) e alterações químicas (formação de novos grupos químicos e diminuição da massa molar $)^{5}$. A radiação UV associada à umidade pode aumentar a degradação do material polimérico. As microtrincas geradas pela exposição do material facilitam a penetração da umidade no material. O vapor de água gerado pode remover produtos solúveis provenientes das reações foto-oxidativas e expõe novas superfícies à radiação ${ }^{6}$. $\mathrm{O}$ comportamento de materiais compósitos quando expostos à radiação UV é ainda um campo pouco explorado, devido à complexidade das interações entre os componentes e os produtos oriundos da degradação ${ }^{5}$.

As técnicas atualmente disponíveis de união de compósitos podem ser classificadas por fixação mecânica, união adesiva e união por fusão (soldagem). No entanto, dentre essas técnicas, destacam-se os processos de soldagem, pois proporcionam melhor qualidade nas juntas, necessitando de menor tempo de processo e pouca preparação da superfície a ser soldada ${ }^{7}$. Um dos processos que vêm sendo adaptados para a soldagem desses materiais é o processo oxigás, em que a combustão de dois gases é utilizada como fonte de calor, e que apresenta a possibilidade de controle da temperatura durante o processo e seu baixo custo como vantagens ${ }^{8}$. O processo oxigás utilizando acetileno já é bem difundido para corte e solda em materiais metálicos, entretanto pouca literatura ou publicações são encontradas para materiais compósitos. Nesse sentido, este estudo tem como objetivo a caracterização de juntas soldadas de compósito de polieterimida (PEI)/fibra de carbono pelo processo oxiacetileno, frente aos condicionamentos ambientais por radiação UV e higrotérmico.

\section{MATERIAIS E MÉTODOS}

\section{Laminados}

Para o desenvolvimento deste trabalho foram utilizadas amostras do laminado PEI/fibras de carbono, nas dimensões $100 \times 25 \mathrm{~mm}$, confeccionados com tecidos na configuração 8 HS com espessuras nominais entre 2,0 a 3,5 mm, e com configuração $(0 / 90)_{\mathrm{fc}}$ contendo aproximadamente $50 \%$ em volume de matriz.

\section{Soldagem oxiacetileno}

Para a soldagem foi utilizado um conjunto de cilindros oxiacetileno, promovendo chama neutra com vazões de $1,0 \mathrm{kgf} / \mathrm{cm}^{3} \mathrm{de}$ acetileno e de $0,5 \mathrm{kgf} / \mathrm{cm}^{3}$ de oxigênio. Para o controle da temperatura, foi utilizado um pirômetro óptico da marca Instrutherm. Durante o processo de soldagem, as amostras foram posicionadas e fixadas em um dispositivo desenvolvido por Carvalho e Oliveira $^{9}$ que consiste em dois tijolos refratários, como apresentado na Fig. 1, possuindo dois orifícios para a passagem da chama.

Uma placa da liga de alumínio 2024-T3 nas dimensões $25 \times 25 \mathrm{~mm}$ foi utilizada no orifício de recebimento da chama como proteção e para condução térmica. Os parâmetros para a soldagem foram: tempo de $50 \mathrm{~s}$ e distância da chama de $50 \mathrm{~mm}$. 


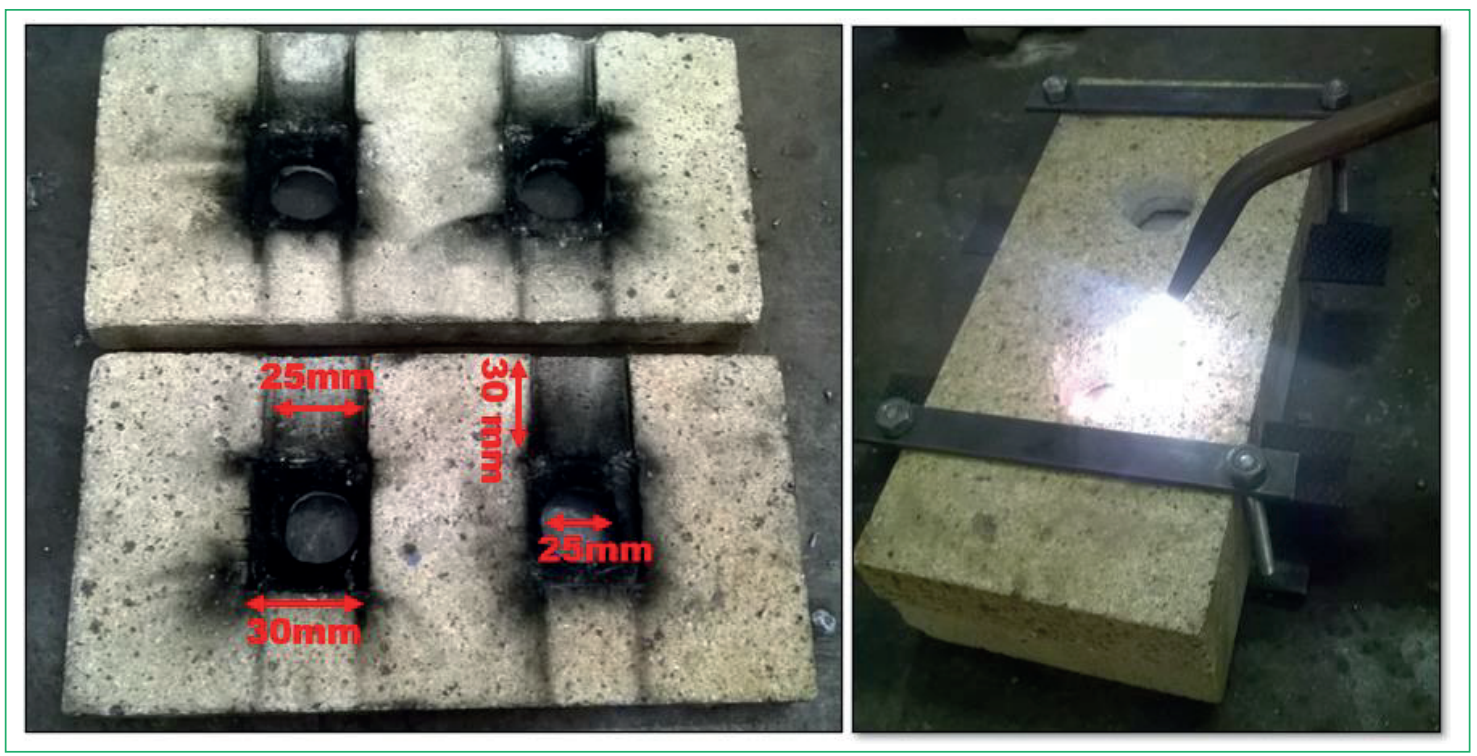

Figura 1: Dispositivo utilizado na soldagem com dimensões.

\section{Condicionamentos ambientais}

As amostras foram inicialmente submetidas a um processo de secagem em estufa a vácuo (marca QUIMIS, modelo Q819V2) para a realização dos ensaios de condicionamento higrotérmico e por radiação UV. Após essa etapa, as amostras foram pesadas e colocadas em estufa a $80^{\circ} \mathrm{C}$, durante um período de $12 \mathrm{~h}$, até que ocorresse a estabilização da massa e a presença de umidade fosse mínima. A perda de umidade foi calculada a partir da Eq. 1.

$$
\% \text { perda de massa: } \frac{\left(M_{u}-M_{S}\right)}{M_{u}}
$$

onde: $M_{u}=$ massa úmida; $M_{s}=$ massa seca.

\section{Condicionamento higrotérmico}

Cinco juntas soldadas foram condicionadas em uma câmara higrotérmica (marca Marconi modelo MA 835/UR), com temperatura de $80^{\circ} \mathrm{C}$ e umidade relativa de $90 \%$. Os ensaios foram realizados baseando-se na norma ASTM D5229/ D5229M - 14e $1^{10}$. Para acompanhamento do ganho de massa, foram utilizadas duas amostras de acompanhamento, pesadas durante todo o período de condicionamento, inicialmente diariamente até o $7^{\circ}$ dia, depois a cada 4 dias, e por fim uma vez a cada 7 dias, até que a estabilização das massas fosse observada, sendo então retiradas e pesadas todas as amostras. O valor do ganho de massa pode ser calculado a partir da Eq. 2.

$$
\text { \% Ganho de Massa: } \frac{\left(M_{u}-M_{S}\right)}{M_{u}} 100
$$

onde: $M_{u}=$ massa úmida; $M_{s}=$ massa seca.

\section{Condicionamento ultravioleta (UV)}

Cinco amostras permaneceram expostas ao condicionamento por radiação UV em uma câmara de condicionamento Ultravioleta (marca Q-Lab modelo QUV) durante 1.200 h, com um ciclo de 8 radiações UV e 4 h de condensação. Os ensaios foram realizados na Faculdade de Engenharia de Guaratinguetá, baseando-se na norma ASTM G154 - $16^{11}$.

\section{Caracterização mecânica}

\section{Lap shear (LSS)}

Os ensaios de lap shear foram realizados em uma máquina universal de ensaios (Shimadzu modelo AG-X), apresentada na Fig. 2, com uma célula de carga de $50 \mathrm{kN}$, baseando-se nas normas ASTM D1002 - $10^{12}$ e ASTM D5868 - 01 ${ }^{13}$. As amostras foram posicionadas nas garras da máquina de ensaio universal e tracionadas a $1,5 \mathrm{~mm} / \mathrm{min}(0,05 \mathrm{in} / \mathrm{min})$ até que ocorra a falha. 


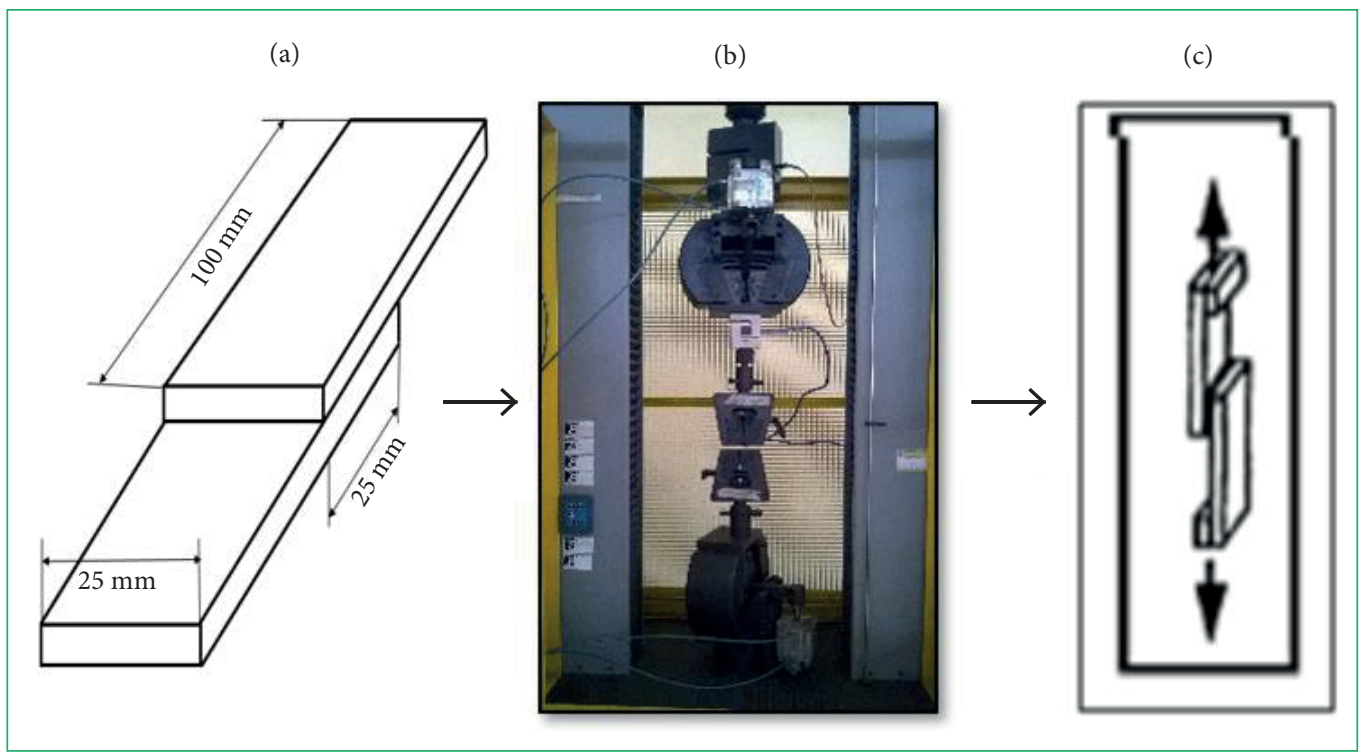

Figura 2: (a) Dimensões das amostras do ensaio lap shear; (b) máquina utilizada no ensaio e (c) esquematização do ensaio.

\section{Interlaminar short beam (ILSS)}

O ensaio de interlaminar short-beam strength (ILSS) foi realizado com o intuito de avaliar a resistência ao cisalhamento interlaminar das juntas soldadas com e sem submissão aos condicionamentos ambientais. Os ensaios foram realizados com uma célula de carga de 10 kN em uma máquina universal de ensaios mecânicos (marca Shimadzu, modelo AG-X). Os ensaios foram realizados na Faculdade de Engenharia de Guaratinguetá de acordo com a norma ASTM D2344 / D2344M - 16 ${ }^{14}$. A equação para a obtenção dos valores de resistência ao cisalhamento interlaminar encontra-se apresentada na Eq. 3.

$$
\Gamma=\frac{3}{4} x \frac{P}{W t}
$$

onde: $\Gamma=$ resistência ao cisalhamento interlaminar; $\mathrm{P}=\operatorname{carga}$ na falha $(\mathrm{N}) ; \mathrm{W}=\operatorname{largura}(\mathrm{mm}) ; \mathrm{t}=\operatorname{espessura}(\mathrm{mm})$.

\section{Caracterização microestrutural}

Após a realização dos testes de condicionamento ambiental, as amostras foram submetidas a ensaios mecânicos para a avaliação do efeito do condicionamento na resistência mecânica da junta. Elas foram lixadas em lixas d'água com granulometria de 320, 600 e 1200, e polidas com pasta de diamante de granulometria de $1 \mu \mathrm{m}$. Para obtenção da microscopia e macroscopia das amostras foram utilizados um microscópio óptico (marca Zeiss modelo Vert A1) com aumento de 50 a $1000 \times$ e um estereoscópio (marca Olympus) com aumento de 6,7 a $45 \times$.

\section{RESULTADOS E DISCUSSÃO}

\section{Condicionamentos ambientais}

\section{Condicionamento higrotérmico}

Os efeitos causados pela ação da umidade em materiais compósitos devem ser levados em consideração na realização de projetos em geral. A umidade penetra na fase matriz do material através da difusão até que o equilíbrio seja atingido, sendo esse processo acentuado quando em conjunto com a temperatura. A absorção de umidade pode gerar a expansão da matriz polimérica causando lesões internas e resultar na redução da resistência mecânica e rigidez do material, gerando também mudanças nas características físico-química da matriz ${ }^{6}$. A Fig. 3 apresenta o ganho de massa das amostras em porcentagem.

Analisando-se a curva obtida, observa-se que o ganho de umidade pelas amostras cresce com o tempo, sendo cerca de $0,48 \%$. Na primeira semana de ensaio, as amostras absorveram a água mais rapidamente até que atingissem um estado chamado de pseudoequilíbrio. No final do ensaio, observou-se um ganho de massa das amostras devido à absorção de umidade que, depois de certo tempo, tende a penetrar na matriz polimérica a partir do processo de difusão, tornando a absorção de umidade mais lenta, como observado por Quan ${ }^{6}$ e Reis ${ }^{15}$. 


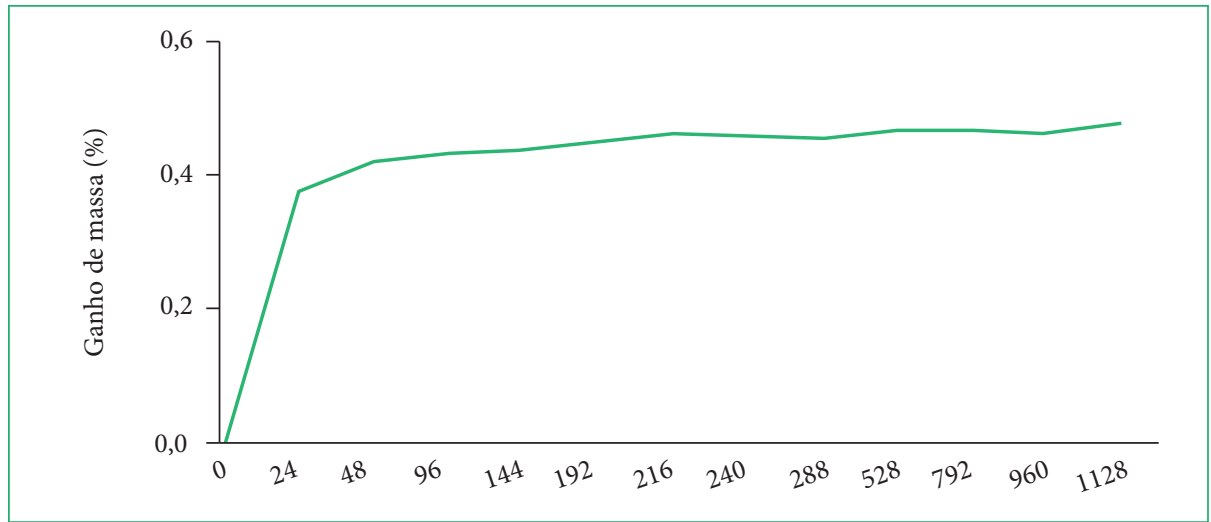

Figura 3: Média do ganho de massa das amostras soldadas de PEl/fibra de carbono submetidas ao condicionamento higrotérmico.

\section{Condicionamento por radiação ultravioleta}

Na Fig. 4 é apresentada a curva de perda de massa do material submetido ao condicionamento por radiação UV, considerando que, a partir da segunda semana, houve efetivamente o efeito do condicionamento na degradação do material.

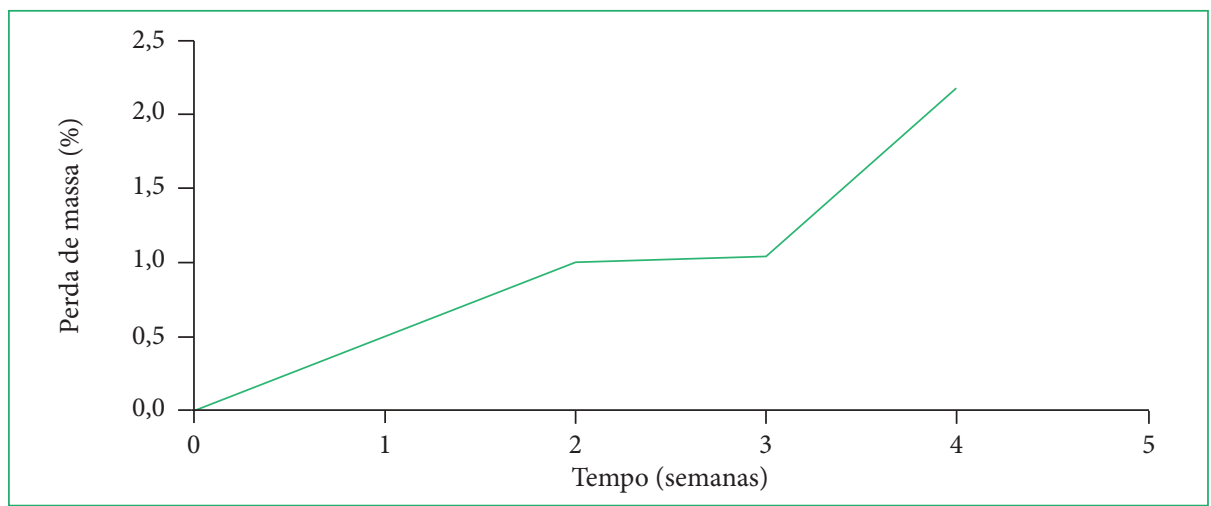

Figura 4: Média da perda de massa das amostras soldadas de PEI/ fibra de carbono submetido ao condicionamento UV.

A partir dessa análise, observou-se na amostra que houve um ganho de massa de 14,28 para 14,33 g (em torno de 0,33\%) na primeira semana, provavelmente devido à absorção de umidade pelo laminado. Já entre a segunda e terceira semana, constatou-se perda de massa, de 14,33 para 14,14 g. Entre a terceira e a quarta semana, a massa permaneceu sem muita variação, enquanto que da quarta para a quinta semana perdeu cerca de 0,16 g. Dessa forma, é possível observar a ocorrência de perda de massa de aproximadamente 2,51\%. Possivelmente, a perda de massa do material após condicionamento por radiação UV se dá pela liberação de moléculas de água e voláteis, e também pela degradação do material devido aos efeitos de foto-oxidação causada pela radiação ${ }^{16}$.

\section{Caracterização mecânica}

\section{Lap shear (LSS)}

Após a estabilização do ganho de massa das amostras submetidas às câmaras de climatizações higrotérmica e ultravioleta, foi realizado o ensaio mecânico lap shear para a verificação da resistência a tração da junta. Os valores obtidos são apresentados na Tabela 1.

Tabela 1: Resistência mecânica das amostras submetidas aos condicionamentos higrotérmico e ultravioleta.

\begin{tabular}{|c|c|c|c|}
\hline & \multicolumn{3}{|c|}{ Lap shear (MPa) } \\
\hline Amostra & Material soldado & Condicionamento higrotérmico & Condicionamento ultravioleta \\
\hline 1 & 14,22 & 8,70 & 5,20 \\
\hline 3 & 14,12 & 11,37 & 2,40 \\
\hline 4 & 15,82 & 10,30 & 0,85 \\
\hline 5 & 15,55 & 9,10 & 14,39 \\
\hline Média & 14,58 & 6,42 & 9,47 \\
\hline
\end{tabular}


Observa-se que os valores de resistência mínimos e máximos obtidos no ensaio lap shear das amostras não condicionadas foram de 14,12 e 15,82 MPa, respectivamente. Nos compósitos submetidos ao condicionamento higrotérmico, esses valores foram de 6,42 e 11,37 MPa, respectivamente, enquanto que no condicionamento ultravioleta os valores foram de 0,85 até 14,39 MPa, respectivamente. Durante essa avaliação, foi também observada uma diminuição nos valores de resistência mecânica das amostras condicionadas quando comparados aos provenientes do material como recebido (diminuição de 38,1 e 56,4\%, em laminados submetidos aos condicionamentos higrotérmico e por radiação ultravioleta, respectivamente).

\section{Interlaminar short beam (ILSS)}

Os valores de resistência interlaminar das juntas soldadas em comparação às juntas submetidas aos condicionamentos higrotérmico e por radiação UV são apresentadas na Tabela 2. Os resultados obtidos após a realização do ensaio ILSS mostram que houve uma pequena perda de resistência ao cisalhamento interlaminar das amostras submetidas aos condicionamentos, sendo essa diminuição de 9,7\% para amostras condicionadas em câmara higrotérmica e de 18,9\% para amostras condicionadas em câmara de radiação UV.

Tabela 2: Resistência interlaminar das juntas submetidas aos condicionamentos higrotérmico por radiação UV.

\begin{tabular}{c|c|c|c|}
\hline \multicolumn{3}{|c|}{ ILSS (MPa) } \\
\hline Amostra & Material soldado & Condicionamento higrotérmico & Condicionamento ultravioleta \\
\hline 1 & 24,30 & 20,17 & 12,01 \\
\hline 2 & 27,23 & 27,45 & 35,32 \\
3 & 32,20 & 27,18 & 26,05 \\
4 & 31,10 & 30,00 & 25,42 \\
\hline 5 & 35,86 & 31,12 & 24,60 \\
\hline Média & 30,10 & 27,18 & 24,40 \\
\hline
\end{tabular}

Uma informação relevante fornecida neste estudo é a comparação com os resultados obtidos por Abrahão ${ }^{17}$, que obteve a resistência interlaminar do material compósito PEI/fibra de carbono como recebido sendo em média de 47,95 MPa. Em comparação aos valores de resistência interlaminar de amostras do material, tanto as juntas soldadas quanto as amostras condicionadas pelos dois ensaios, foi observada diminuição de resistência mecânica, sendo de 37,2\% para junta soldada, 43,3\% em amostras condicionadas em câmara higrotérmica e 49,9\% em amostras condicionadas em câmara por radiação UV, quando comparadas às amostras do compósito como recebido.

\section{Caracterização morfológica das amostras fraturadas}

Lap shear (LSS)

\section{Junta não condicionada}

Após a realização do ensaio lap shear, observou-se a ocorrência da fratura do tipo intralaminar nas amostras que não foram submetidas aos condicionamentos. Durante o desenvolvimento deste trabalho, a microestrutura dessas juntas foi analisada para posterior verificação comparativa. A microestrutura da amostra da junta rompida no ensaio LSS do material soldado não submetido aos condicionamentos ambientais que apresentou maior valor de resistência é apresentada na Fig. 5. Evidencia-se a presença de vazios na região da resina

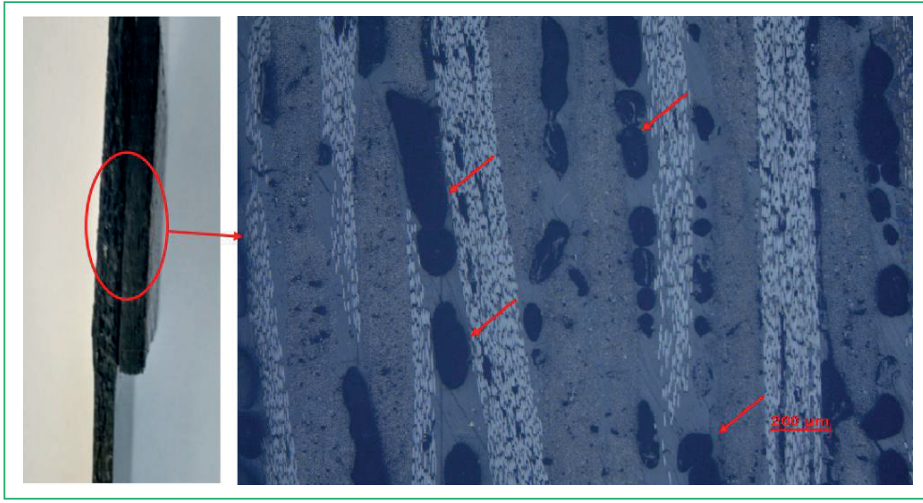

Figura 5: Microscopia óptica da amostra que apresentou maior valor de resistência obtido com ampliação de 50 x. 
polimérica (indicada pelas setas vermelhas) devido a um eficiente processo de soldagem e como resultado do ensaio mecânico realizado. Também pode ser observado que não há degradação da área da fibra, o que explica seu elevado valor de resistência mecânica, já que esta é responsável por fornecer resistência ao material compósito.

\section{Condicionamento higrotérmico}

A Fig. 6 apresenta a microscopia da junta que apresentou maior valor de resistência após ser submetida ao condicionamento higrotérmico e realização do ensaio mecânico lap shear. A partir dos resultados provenientes da microscopia óptica da amostra, é possível observar a presença de vazios na região da matriz (setas amarelas) e de rompimentos nas regiões fibrosas (setas pretas). Ao se comparar a microscopia das amostras submetidas ao condicionamento higrotérmico com a do material como recebido, observa-se que há maior presença de vazios na matriz e expansão das fibras no material condicionado devido à difusão da umidade e quebra das cadeias, o que, de acordo com Quan' ${ }^{6}$, resulta na diminuição da resistência e rigidez do material.

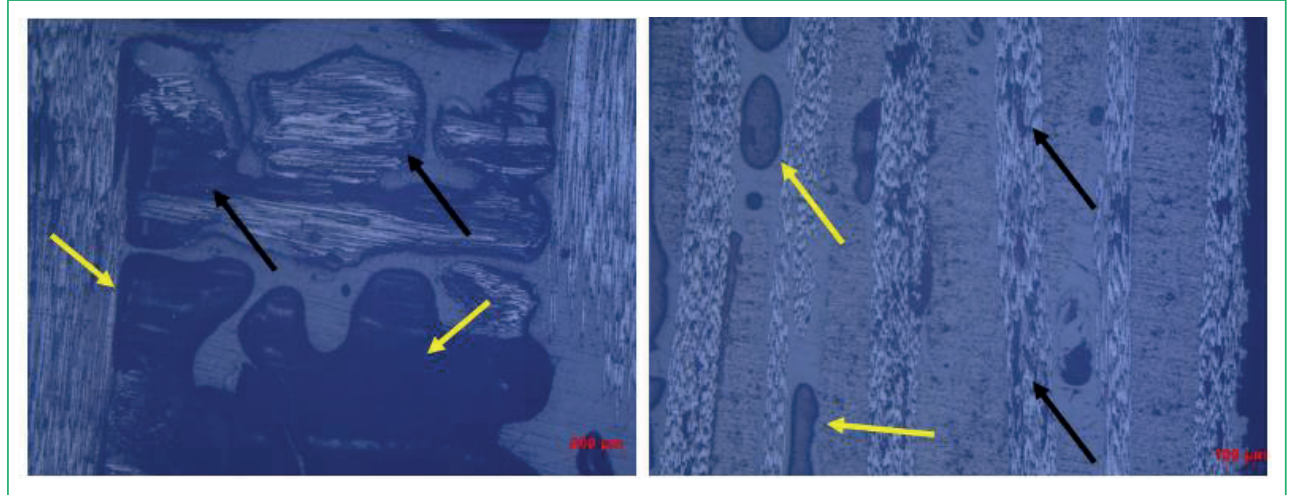

Figura 6: Microscopia da junta submetida ao condicionamento higrotérmico com ampliação de 50 x.

\section{Condicionamento ultravioleta (UV)}

Os resultados provenientes da microscopia da junta soldada submetida ao condicionamento por radiação ultravioleta são apresentados na Fig. 7 com ampliação de $50 \times$. Analisando as imagens obtidas a partir da microscopia óptica, é possível verificar que a ação da umidade juntamente com a dos raios UV gerou vazios na fase matriz e causou degradação da área fibrosa, devido à liberação de moléculas de água e pela foto-oxidação; o que resultou na elevada diminuição de resistência mecânica do material condicionado quando comparado com o recebido. De acordo com Oliveira ${ }^{5}$, a radiação UV, em se tratando de um ambiente não penetrante, causa a degradação superficial de materiais compósitos. Entretanto neste caso a soldagem causou fragilização, permitindo, assim, a penetração dos raios UV e causando a degradação das fibras internas do material.

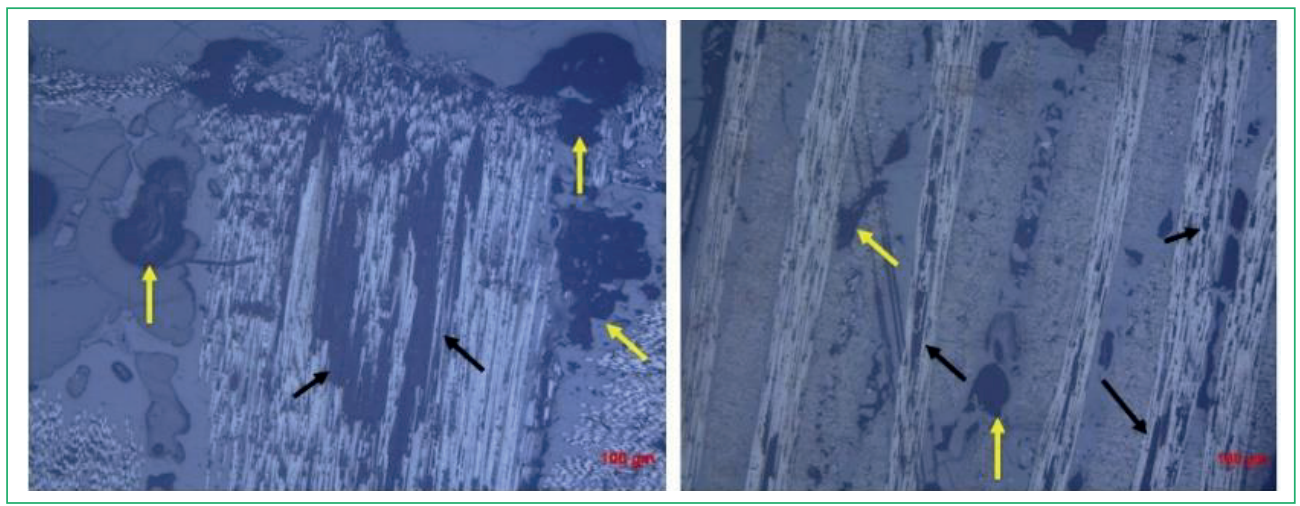

Figura 7: Microscopia da amostra condicionada por radiação ultravioleta que apresentou maior valor de resistência, com ampliação de 50 x.

Interlaminar short beam (ILSS)

\section{Junta não condicionada}

A microscopia óptica foi realizada com o intuito de analisar a fratura ocorrida nas amostras. A micrografia da junta soldada que não foi submetida ao condicionamento ambiental é apresentada na Fig. 8. Observa-se a ocorrência das fraturas translaminares em modo 3 , 
que, segundo Marinucci ${ }^{18}$, são as que ocorrem transversalmente ao plano do laminado, tendo como característica a ruptura das fibras. A partir dessa análise, a ocorrência de delaminações em sentido transversal ao carregamento utilizado.

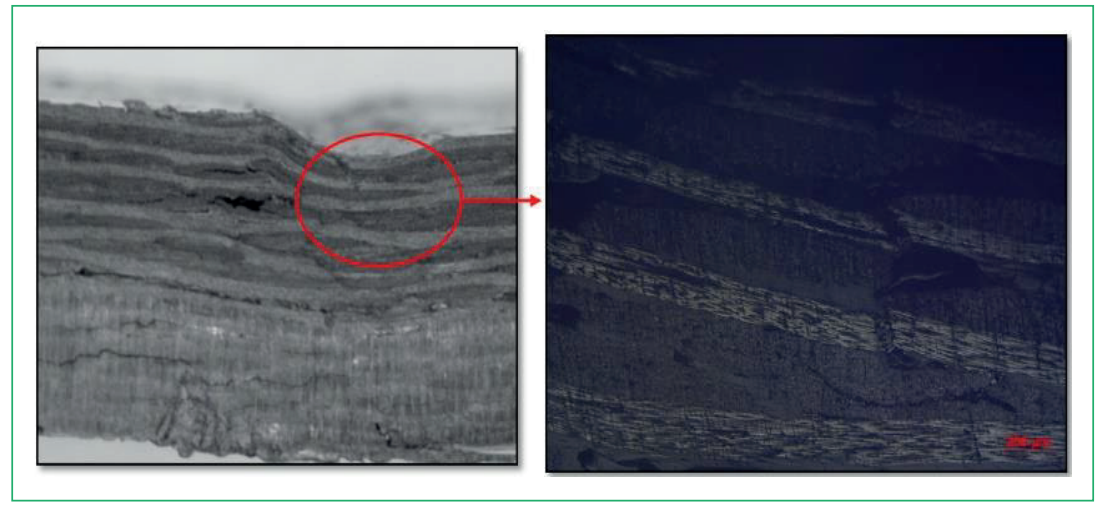

Figura 8: Microscopia da junta soldada sem exposição a condicionamentos ambientais com ampliação de $50 \times$.

\section{Condicionamento higrotérmico}

A Fig. 9 apresenta a microscopia da junta soldada após condicionamento higrotérmico e realização do ensaio mecânico ILSS. Verifica-se a ocorrência de fraturas intralaminar e interlaminar em modo 2 na junta pós-condicionamento, que, de acordo com Bandeira ${ }^{19}$, caracterizase pela ocorrência da fratura entre as lâminas do compósito, conforme pode ser observado na microscopia da amostra a presença de delaminações transversais ao carregamento utilizado. Constata-se também que não houve propagação da trinca em toda a extinção da amostra ensaiada, tendo se prolongado apenas próximo ao local do carregamento, não atingindo assim a interface soldada do material.

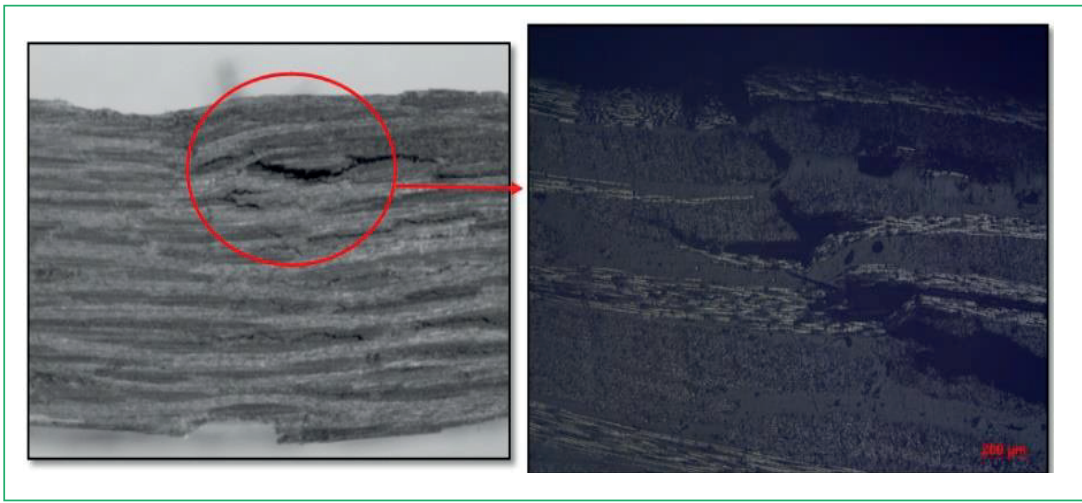

Figura 9: Microscopia da junta soldada com exposição ao condicionamento higrotérmico com ampliação de 50 x.

\section{Condicionamento ultravioleta}

A Fig. 10 apresenta a microscopia da amostra da junta soldada submetida ao condicionamento por radiação ultravioleta com ampliação de $50 \times$. A partir da microscopia nota-se a ocorrência de delaminações em sentido paralelo ao das camadas do laminado, caracterizando, assim, a fratura do tipo interlaminar em modo 2. Observa-se também que não houve propagação de trinca na amostra ensaiada.

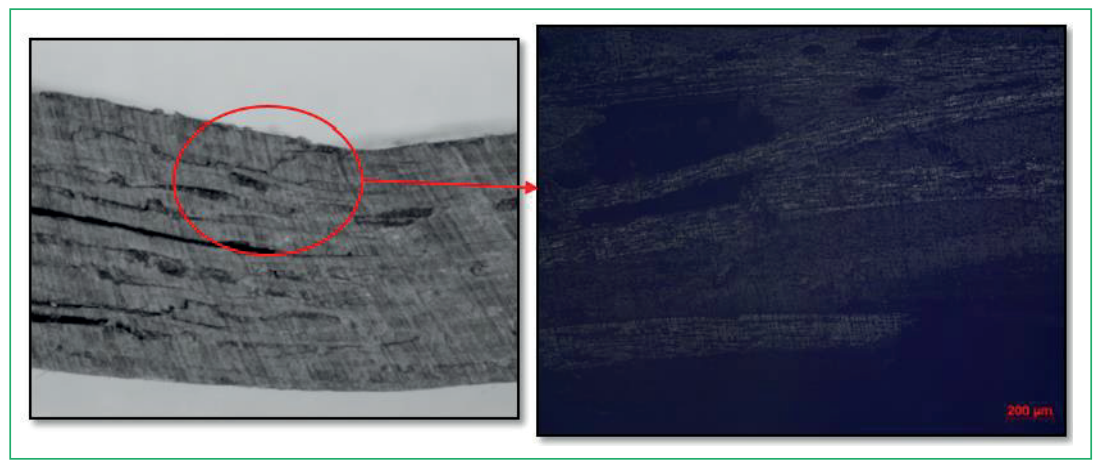

Figura 10: Microscopia da junta soldada com exposição ao condicionamento ultravioleta com ampliação de 50 x. 


\section{CONCLUSÃO}

No ensaio de condicionamento ambiental higrotérmico observou-se um ganho de massa inicial nas primeiras 24 horas de ensaio. Após esse período, o material atingiu o pseudoequilíbrio, quando passou a absorver a umidade mais lentamente e em menor quantidade até que sua massa passou a ser estável. Notou-se também a ocorrência de uma diminuição significativa da resistência mecânica devido à plasticização da resina e da quebra de fibras devido à difusão Fickiana.

No condicionamento ultravioleta foi observado um ganho de massa entre a primeira e segunda semana de ensaio, enquanto que entre a segunda e quinta semana houve uma queda de massa devido à fotodegradação. Notou-se também uma queda significativa na resistência mecânica do material devido à degradação causada pela radiação ultravioleta.

Ao comparar as microscopias pós-ensaios mecânicos de LSS e ILSS dos ensaios de condicionamento e da junta soldada, observou-se que não houve ocorrência de degradação da matriz polimérica no ensaio UV; no entanto verificou-se a presença de grandes vazios na resina na amostra do condicionamento higrotérmico devido à absorção da umidade. Tanto nos ensaios higrotérmico e UV observou-se a ocorrência da degradação da fibra em grandes dimensões, o que provavelmente ocorreu devido ao processo de soldagem, que causou a fragilização das juntas e permitiu a penetração e a ação dos condicionamentos nas fibras internas do material.

\section{AGRADECIMENTOS}

Os autores agradecem a empresa Toray Composites pelo fornecimento das amostras de compósitos de PEI/fibras de carbono.

\section{FINANCIAMENTO}

Fundação de Amparo à Pesquisa do Estado de São Paulo [https://doi.org/10.13039/501100001807]

Processos 2009/06335-9 e 2017/16970-0

Conselho Nacional de Desenvolvimento Científico e Tecnológico [https://doi.org/10.13039/501100003593]

Processo 303224/2016-9

\section{REFERÊNCIAS}

1. Rosa BM. Avaliação do condicionamento higrotérmico em compósitos fibra de carbono/epóxi e titânio anodizado [Dissertação]. [Guaratinguetá]: Universidade Estadual Paulista; 2017.

2. Damato CA. Efeito do condicionamento ambiental nas propriedades de cisalhamento e viscoelásticas de compósitos híbridos metal-fibra [Dissertação]. [Guaratinguetá]: Universidade Estadual Paulista; 2010.

3. Costa AP, Botelho EC, Pardini LC. Efeito da degradação ambiental nas propriedades de cisalhamento de compósitos PPS/fibra de carbono. Polímeros. 2011;21(3):161-7. https://doi.org/10.1590/S0104-14282011005000042

4. Botelho EC, Scherbakoff N, Rezende MC, Kawamoto AM, Sciamareli J. Synthesis of polyamide 6/6 by interfacial polycondensation with the simultaneous impregnation of carbon fibers. Macromolecules. 2001;34(10):3367-75. https://doi.org/10.1021/ma000902k

5. Oliveira CFP, Demarquette NR, Carastan DJ, Fechine GJM. Fotodegradação de compósitos de poliestireno/argila montmorilonita: efeito do tipo de argila e presença de sal. Polímeros. 2012;22(1):13-21. https://doi.org/10.1590/S0104-14282012005000010

6. Quan NDG. Análise comparativa da performance de elementos resistivos na soldagem por resistência elétrica em compósitos PEl/fibras de carbono [Monografia]. [Guaratinguetá]: Universidade Estadual Paulista; 2016.

7. Souza SDB. Avaliação dos parâmetros de soldagem para compósitos de PPS/fibras contínuas com aplicações aeronáuticas [Dissertação]. [Guaratinguetá]: Universidade Estadual Paulista; 2013.

8. Bracarense AQ. Processo de soldagem com chama oxi-gás - OFW. Apostila de Soldagem; 2000. [citado em: 01 Ago. 2020]. Disponível em: http://asmtreinamentos.com.br/downloads/soldador/arquivo27.pdf

9. Carvalho TP, Oliveira VS. Desenvolvimento e otimização do processo de soldagem por oxi-acetileno para compósito PEl fibra de vidro [Monografia]. [Pindamonhangaba]: Faculdade de Tecnologia de Pindamonhangaba; 2018.

10. ASTM D5229 / D5229M - 14e1. Standard test method for moisture absorption properties and equilibrium conditioning of polymer matrix composite materials. West Conshohocken: ASTM International; 2014. https://doi.org/10.1520/D5229_D5229M-14E01

11. ASTM G154 - 16. Standard practice for operating fluorescent ultraviolet (UV) lamp apparatus for exposure of nonmetallic materials. West Conshohocken: ASTM International; 2016. https://doi.org/10.1520/G0154-16

12. ASTM D1002 - 10. Standard test method for apparent shear strength of single-lap-joint adhesively bonded metal specimens by tension loading (metal-to-metal). West Conshohocken: ASTM International; 2019. https://doi.org/10.1520/D1002-10R19 
13. ASTM D5868 - 01. Standard test method for lap shear adhesion for fiber reinforced plastic (FRP) bonding. West Conshohocken: ASTM International; 2014. https://doi.org/10.1520/D5868-01R14

14. ASTM D2344 / D2344M - 16. Standard test method for short-beam strength of polymer matrix composite materials and their laminates. West Conshohocken: ASTM International; 2016. https://doi.org/10.1520/D2344_D2344M-16

15. Reis JF. Influência do condicionamento higrotérmico no comportamento mecânico de compósitos soldados de PEl/fibras de carbono [Dissertação]. [Guaratinguetá]: Universidade Estadual Paulista; 2016.

16. Batista NL, Botelho EC. Influência do intemperismo no desempenho viscoelástico de laminados PEl/fibras de carbono com aplicações aeroespaciais. In: $10^{\circ}$ Congresso Brasileiro de Polímeros; 2009.

17. Abrahão ABRM. Otimização do processo de soldagem por resistência elétrica em compósitos PEl/fibras contínuas para aplicações aeronáuticas [Tese]. [Guaratinguetá]: Universidade Estadual Paulista; 2015.

18. Marinucci G. Desenvolvimento, fabricação e análise de falha e fratura de cilindros de fibra de carbono colapsados por pressão interna [Tese]. [São Paulo]: Universidade de São Paulo; 2001

19. Bandeira CF. Obtenção e caracterização de compósitos de benzoxazina/fibra de carbono [Tese]. [Guaratinguetá]: Universidade Estadual Paulista; 2015. 